\title{
Priority Given to Technology in Government-Based Mental Health and Addictions Vision and Strategy Documents: Systematic Policy Review
}

\author{
Shalini Lal ${ }^{1,2,3}$, BScOT, MSc, PhD; Lyna Siafa ${ }^{2,4}$; Hajin Lee ${ }^{1,2}$, PhD; Carol E Adair ${ }^{5,6}$, PhD \\ ${ }^{1}$ School of Rehabilitation, Faculty of Medicine, University of Montréal, Montréal, QC, Canada \\ ${ }^{2}$ Youth Mental Health and Technology Lab, Health Innovation and Evaluation Hub, University of Montréal Hospital Research Centre, Montréal, QC, \\ Canada \\ ${ }^{3}$ Prevention and Early Intervention Program for Psychosis and ACCESS Open Minds, Douglas Mental Health University Institute, Montréal, QC, \\ Canada \\ ${ }^{4}$ Department of Medicine, McGill University, Montréal, QC, Canada \\ ${ }^{5}$ Department of Psychiatry, Cumming School of Medicine, University of Calgary, Calgary, AB, Canada \\ ${ }^{6}$ Department of Community Health Sciences, Cumming School of Medicine, University of Calgary, Calgary, AB, Canada
}

\section{Corresponding Author:}

Shalini Lal, BScOT, MSc, PhD

School of Rehabilitation

Faculty of Medicine

University of Montréal

PO Box 6128, Centre-ville station

Montréal, QC, H3C 3J7

Canada

Phone: 15148908000 ext 31581

Email: shalini.lal@umontreal.ca

\section{Abstract}

Background: The use of information and communication technologies (ICTs) to deliver mental health and addictions (MHA) services is a global priority, especially considering the urgent shift towards virtual delivery of care in response to the COVID-19 pandemic. It is important to monitor the evolving role of technology in MHA services. Given that MHA policy documents represent the highest level of priorities for a government's vision and strategy for mental health care, one starting point is to measure the frequency with which technology is mentioned and the terms used to describe its use in MHA policy documents (before, during, and after COVID-19). Yet, to our knowledge, no such review of the extent to which ICTs are referred to in Canadian MHA policy documents exists to date.

Objective: The objective of this systematic policy review was to examine the extent to which technology is addressed in Canadian government-based MHA policy documents prior to the COVID-19 pandemic to establish a baseline for documenting change.

Methods: We reviewed 22 government-based MHA policy documents, published between 2011 and 2019 by 13 Canadian provinces and territories. We conducted content analysis to synthesize the policy priorities addressed in these documents into key themes, and then systematically searched for and tabulated the use of 39 technology-related keywords (in English and French) to describe and compare jurisdictions.

Results: Technology was addressed in every document, however, to a varying degree. Of the 39 searched keywords, we identified 22 categories of keywords pertaining to the use of technology to deliver MHA services and information. The 6 most common categories were tele $(\mathrm{n}=16 / 22)$, phone $(\mathrm{n}=12 / 22)$, tech $(\mathrm{n}=11 / 22)$, online $(\mathrm{n}=10 / 22)$, line $(\mathrm{n}=10 / 22)$, and web $(\mathrm{n}=10 / 22)$, with $\mathrm{n}$ being the number of policy documents in which the category was mentioned out of 22 documents. The use of terms referring to advanced technologies, such as virtual $(\mathrm{n}=6 / 22)$ and app $(\mathrm{n}=4 / 22)$, were less frequent. Additionally, policy documents from some provinces and territories (eg, Alberta and Newfoundland and Labrador) mentioned a diverse range of ICTs, whereas others described only 1 form of ICT.

Conclusions: This review indicates that technology has been given limited strategic attention in Canadian MHA policy. Policy makers may have limited knowledge on the evidence and potential of using technology in this field, highlighting the value for knowledge translation and collaborative initiatives among policy makers and researchers. The development of a pan-Canadian 
framework for action addressing the integration and coordination of technology in mental health services can also guide initiatives in this field. Our findings provide a prepandemic baseline and replicable methods to monitor how the use of technology-supported services and innovations emerge relative to other priorities in MHA policy during and after the COVID-19 pandemic.

(J Med Internet Res 2021;23(5):e25547) doi: 10.2196/25547

\section{KEYWORDS}

e-mental health; digital mental health; virtual care; technology; mental health; addictions; review; policy; e-health; mHealth; digital health; tele

\section{Introduction}

According to a Canadian survey conducted in 2018 [1], approximately 5.3 million individuals aged 12 years and older reported a need for mental health care in the previous year, yet the mental health needs of almost half of these individuals were unmet. The need to improve access and quality of mental health and addictions (MHA) services is increasingly reflected in Canadian mental health policy and practice [2]. Moreover, consequences of COVID-19 have compounded the need for mental health services [3,4], with concurrent public health guidelines for social distancing creating additional challenges to the delivery of care. These challenges have driven rapid integration of technology into the MHA system [5-8].

The use of the internet and related information and communication technologies (ICTs) to deliver or enhance mental health services (also referred to as digital mental health/digital health, e-mental health/e-health, telehealth, or virtual care) is well recognized for its potential in helping to overcome some of the barriers that individuals face in accessing mental health care [9-12]. For example, compared to conventional approaches, the use of ICTs can provide more accessible, empowering, and sustainable care [11-14]; improve access to specialist mental health care; and reduce wait times [15]. This is particularly important for rural and remote areas that have inequitable access to mental health services due to geographic distance and scarcity of resources, and for populations that are less inclined to seek help in person due to stigma $[11,12]$. Moreover, opportunities to receive care via ICTs also have the potential to provide individuals choice and control over their care [16].

A wide range of ICTs (eg, telephone and videoconferencing services, websites, smartphone apps, social media) have been used to develop innovations that deliver mental health services $[11,12]$. In general, these innovations serve the purpose of providing information and self-management tools; conducting screening and assessment; facilitating monitoring of symptoms, activities, and behaviors; and delivering psychological and social interventions (eg, peer support, counseling, case management) $[11,12]$. Examples include telephone-based crisis interventions [17], psychiatric assessment and treatment via videoconferencing (also known as telepsychiatry) [18,19], web-based therapeutic interventions [20,21], behavioral and psychosocial treatments using smartphone software apps and secured websites [22,23], use of sensors for patient monitoring [24], online peer support through social media [25], and virtual reality therapies [26].

In terms of evidence, there is increasing research indicating the efficacy of using ICTs to deliver mental health services and its effectiveness [20,27,28]. For example, a recent review and meta-analysis demonstrated the efficacy of using ICT-based interventions to address eating disorders under controlled trials. Specifically, digital interventions were shown to be more effective than control conditions in reducing risk factors and symptoms in prevention-focused trials and treatment-focused trials [28]. However, other types of individual-level research, including economic analyses, are still needed, in addition to broader analyses, such as studying change at the policy level.

In Canada, innovation, research, and practice on the use of ICTs in mental health care has significantly advanced over the past decade. Several examples of such advancements are provided in the gray and peer-reviewed literature $[10,11]$, including but not exclusive to evidence-based technology-supported initiatives from the Strongest Families Institute (a not-for-profit organization originating from clinical trials conducted at the IWK Health Centre (formerly Izaak Walton Killam Health Centre) in Nova Scotia and onlinetherapyuser.ca (based on clinical research conducted at the University of Regina with eventual sustained funding received from the Saskatchewan Ministry of Health). However, the use of ICTs in mental health care is still a relatively new paradigm [11,29,30], with implementation remaining limited and fragmented [11,29] even within the context of the COVID-19 pandemic. This indicates a systemic gap between evidence and its implementation, which may in part be due to limited guidance on how to translate evidence into policy and competing priorities in research and government contexts [31,32]. More research at the policy level can inform and bridge the evidence-policy-practice gap [33] and can inform effective collaboration on the development of policy among academics, researchers and developers, health care planners and policy makers, practitioners, and consumer representatives [11,29,32].

Mental health policy and action documents have a critical role and responsibility for optimizing technology integration within the mental health care system. The impact of such a role is well illustrated by the policy example of Australia, a country that is at the forefront of integrating technology in the delivery of mental health services. In 2012, the Australian government's Department of Health and Aging produced a policy document entitled, "E-Mental Health Strategy for Australia," which provided a vision for e-mental health services and key areas for action. The strategy also provided guidance on investment and development to advance the field and was created through input from expert advisors representing top researchers within the field, consumer representatives, and executive leads of organizations delivering mental health services using technology [34]. 
The role of technology in mental health policy is even more critical considering the COVID-19 pandemic. Given this, it is important to understand the priority given to technology in government policy and to monitor the advancement of this priority at the policy level before, during, and after the pandemic. In 2017, a systematic review was published with the aim of comparing areas of focus on the use of technology in pediatric mental health care by examining research studies, and government and organizational documents. It included 2 Canadian-based policy documents, 1 at the national level, and 1 from Ontario [32]. However, to our knowledge, no systematic review has focused on the extent to which technology is discussed in mental health policies from all Canadian provinces and territories to date. Thus, the objective of this systematic policy review is to determine the extent to which technology is considered in Canadian-based mental health policy documents. Specifically, we aimed to synthesize the policy priorities addressed in government-based MHA documents and to better understand the extent to which technology is described as having a role in achieving these policy priorities.

\section{Methods}

\section{Collection and Selection of MHA Policy Documents}

As illustrated in Figure 1, we started with an initial set of 19 provincial/territorial $(\mathrm{P} / \mathrm{T})$ policy documents published until
June 2017 that were identified as part of a project led by CEA on the development of a pan-Canadian MHA performance measurement framework [2,35]. These initial documents were obtained from a systematic internet search of P/T government websites. They were then confirmed for completeness for each jurisdiction in consultation with researchers, data managers, and policy makers from the Mental Health Commission of Canada's (MHCC) Provincial and Territorial Advisory Group and through consensus by the research team based on inclusion criteria pertaining to policy timeframes, focus on special populations, and versions of documents [2,35]. Two additional team members from this current review (SL and LS) considered each of these 19 documents to determine if they met our inclusion criterion for the current review and to assess the need for additional searches. The inclusion criterion was a document that describes a P/T vision or strategy for mental health service delivery; we also endeavored to ensure that each P/T was represented by a mental health policy document. In the exceptional case of Nunavut, which became the newest Canadian territory in 1999 at which time a vision or strategy document did not exist, the next closest type of document was included [36]. The exclusion criterion was any older document for which an updated version of the same type of document from that $\mathrm{P} / \mathrm{T}$ was available. This was to provide the most updated perspective of mental health policy across the $\mathrm{P} / \mathrm{T}$ at the time of conducting the review.

Figure 1. Identification and selection of MHA policy documents. MHA: mental health and addictions.

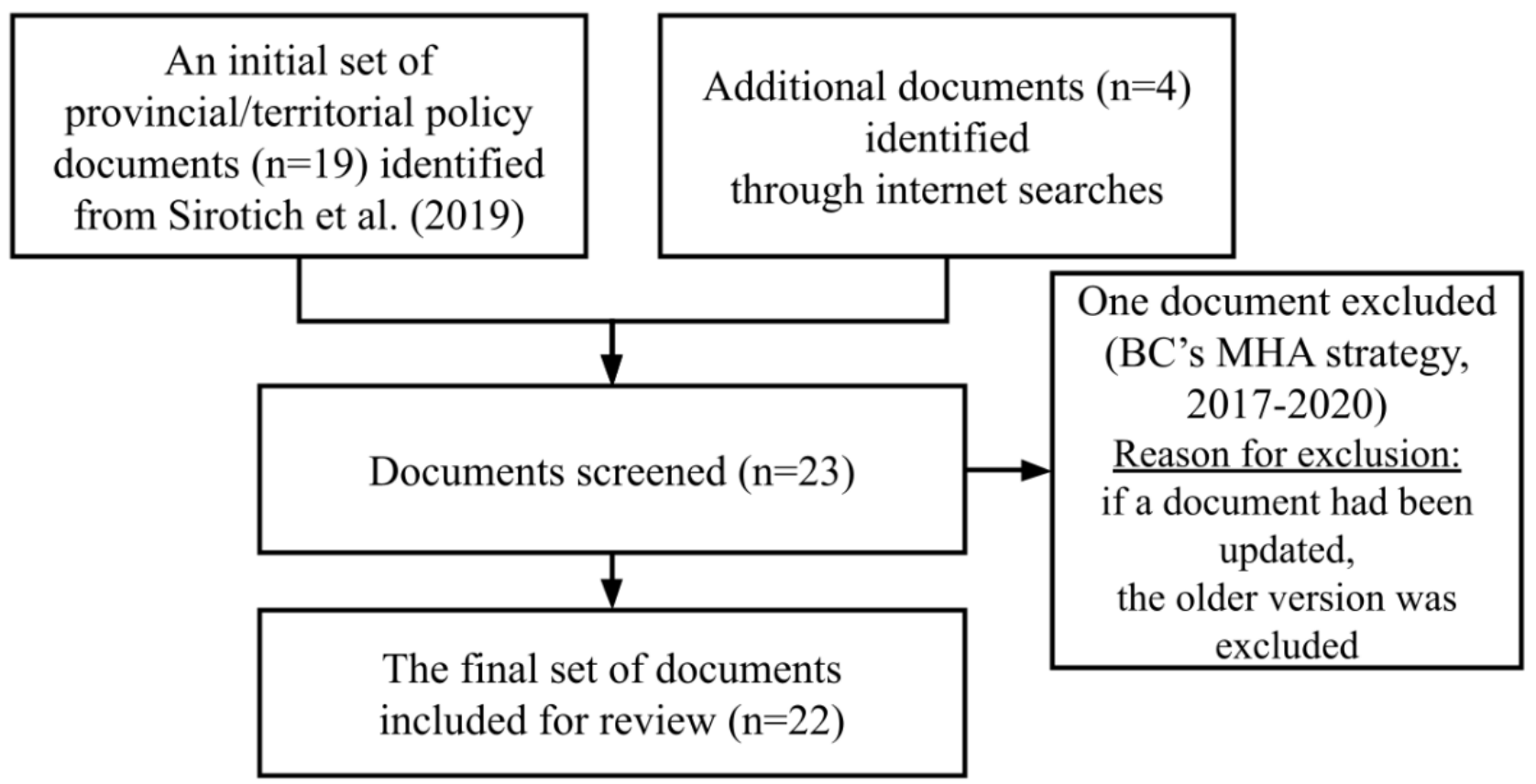

To identify updated versions of the policy documents, during the summer of 2019, we conducted internet searches (on the $\mathrm{P} / \mathrm{T}$ websites and using the Google search engine). Based on this search, we identified 4 additional documents: (1) a recent MHA policy document from British Columbia (2019-2029) [37], (2) Nova Scotia's progress update on the 5-year plan (2016) [38], (3) an action plan for suicide prevention in Nunavut (2016-2017) [39], and (4) the Final Report of Ontario's MHA Leadership Advisory Council (2017) [40]. Thus, we had a total set of 23 documents, from which we excluded 1, BC's MHA Strategy (2017-2020) [41] because a newer version was available; this resulted in a final set of 22 documents. Each of these documents is presented in Multimedia Appendix 1, including title, source in terms of P/T, URL links, and overview.

All documents described a vision or framework, strategy or action plan, or progress update related to MHA policy in that province/territory, 20 documents addressed MHA policies 
pertaining to the $\mathrm{P} / \mathrm{T}$ 's population as a whole, while 2 documents were about MHA policy specific to a subpopulation in that $\mathrm{P} / \mathrm{T}$ (ie, the 2013 BC First Nations and Aboriginal People's MHA 10 Year Plan and the 2014 Yukon's Child and Youth MHA Framework (2014) [42,43].

\section{Data Extraction and Analysis}

We first reviewed the documents using an initial list of 9 technology words (e-mental health, tech, tele, net, internet, web, virtual, app, and digital) to gain a preliminary impression of how technology was considered in the government documents. These 9 words were based on SL and CEA's previous review of the literature on technology in mental health care [12] and recent academic and gray literature (eg, e-mental health documentation from the MHCC [10]). We reviewed the documents systematically using the control-F function and recorded instances where the 9 words were mentioned in a Microsoft Word document table. We did not find many examples of policy documents mentioning the use of technology; however, we felt that perhaps this could have been due to the limited number of words we used to search the documents. The initial search process informed our understanding of the types of terms used in the policy documents and led to the development of a more detailed protocol to guide our review. Our protocol included data extraction tables for organizing the data (eg, name of policy document, year of publication, source, excerpts from the documents illustrating use of a technology term). As part of this protocol, we also created a process for validating the data extraction and analysis to enhance reliability of our results. Our final protocol included 39 technology-related keywords that would be used to examine the extent to which each policy document addressed the topic of technology in relation to the delivery of mental health services. This list was finalized through pilot testing in several of the documents before being implemented systematically across all the documents. We also translated this keywords list into French, first by a native French-speaking team member, with initial validation by a second native French-speaking team member (LS) and final validation by the project lead (SL) who is a native English-speaking team member. The keywords list in English and French is presented in Table 1.

Next, we reviewed each policy document to gain a better understanding of the type of document (ie, vision, strategy, and progress related to mental health policy). We determined the type of document mainly based on their titles, for example, documents that typically used the terms vision, strategy, or update in the titles. We also conducted a modified conventional content analysis [44] of the MHA policy priorities described in these documents to obtain a snapshot of the recurrent themes addressed across the set of 22 documents. This involved reviewing the content of each document with a focus on extracting the MHA priorities using a data extraction table in a Microsoft Excel file (LS). The priorities were then coded inductively (ie, staying close to the terms used) and then grouped to arrive at a list of 14 categories. These categories were then reviewed by 2 members of the team (SL and LS) to discuss overlaps, redundancies, and what each category represented in terms of content. This led to a final coding framework of 10 MHA priorities that were represented across the 22 documents. Finally, each of the documents was then re-examined by LS to tabulate which of the 10 MHA priorities was addressed by each of the P/Ts, and this tabulation was then validated by HL.

Next, using the control-F function, we searched each of the documents using the keyword terms listed in Table 1. All findings that represented the use of technology within the context of mental health care were charted in a Microsoft Excel file. The data in this Excel file were initially extracted by a member of our team (LS) and validated by another (HL).

After we completed the search for the keywords and all instances of the use of technology were extracted from the policy documents, we grouped the 39 keywords into 22 categories to facilitate the synthesis process. Specifically, we merged the synonyms and abbreviations of a keyword into the same category. For example, electronic and the abbreviation EHR (electronic health record) were grouped into the electronic category. We also removed keywords that had not been mentioned in any of the policy documents. For example, EMR (electronic medical record) was removed, since it was not mentioned in any document. This final set of 22 categories was arrived at through an iterative process involving discussion and consensus between SL and LS. We then organized our findings based on the number of policy documents (n) that mentioned each category out of the 22 policy documents (eg, the keyword category Tele was mentioned in 16 out of the 22 policy documents; $n=16 / 22$; Table 2); subsequently, we identified which $\mathrm{P} / \mathrm{Ts}$ had documents mentioning each category (Table 2 ). We also counted the number of categories mentioned by each $\mathrm{P} / \mathrm{T}$ out of the total 22 categories, as represented by $\mathrm{n}$ (eg, only 1 keyword category, electronic, was mentioned by the Northwest Territories; Multimedia Appendix 3). Note that we counted compound keywords twice to maintain a systematic approach to the keyword search of the policy documents. For example, telephone was counted once in tele and once in phone, and text messages was counted once in text and once in messag*. 
Table 1. List of English and French keywords ${ }^{\mathrm{a}}$ used to search the documents.

\begin{tabular}{|c|c|}
\hline Keywords list (English) & Keywords list (French) \\
\hline app (eg, application) & appli (eg, application) \\
\hline artificial intelligence & intelligence artificielle \\
\hline avatar & avatar \\
\hline bots (eg, chatbots, chat bots, robots), chat (eg, live chat, live-chat) & $\begin{array}{l}\text { bots (eg, robots), chat (eg, chatbots, chatter, chat en ligne, chat en direct), } \\
\text { dialogueur, agent conversationnel }\end{array}$ \\
\hline messag*, instant messaging & messagerie instantanée \\
\hline cell, phone, line, link & cellulaire, téléphone \\
\hline mobile (eg, mobile device, mobile health), mhealth & mobile (eg, appareil mobile, santé mobile) msanté (eg, m-Santé, m-santé) \\
\hline text, SMS & message texte, texto, SMS (eg, message-texte) \\
\hline smart (eg, smartphone, smart phone, smart watch, smartwatch) & intelligent (eg, téléphone intelligent, montre intelligente) \\
\hline $\begin{array}{l}\text { computer (eg, laptop computer, desktop computer, personal computer), } \\
\text { laptop }\end{array}$ & ordinateur, portable (eg, ordinateur portable, ordinateur-portable) \\
\hline cyber (eg, cyber-psychology, cyber psychology, cyberspace, cyber-space) & $\begin{array}{l}\text { cyber (eg, cyberpsychologie, cyber-psychologie, cyber psychologie, cyber- } \\
\text { espace, cyber espace) }\end{array}$ \\
\hline $\begin{array}{l}\text { device (eg, wearable device, wearable-device, mobile device, portable } \\
\text { device) }\end{array}$ & appareil (eg, appareil portable) \\
\hline digital & digital \\
\hline e-mental health & $\begin{array}{l}\text { santé mentale électronique, e-santé mentale, santé numérique, cybersanté } \\
\text { mentale }\end{array}$ \\
\hline email & courriel, courrier électronique \\
\hline $\begin{array}{l}\text { electronic, } \mathrm{EMR}^{\mathrm{b}}, \mathrm{EHR}^{\mathrm{c}} \text {, e-referral (eg, mail, electronic-mail, electronic } \\
\text { case management, electronic-case-management, electronic medical record, } \\
\text { electronic-medical-record, e-patient, e patient, electronic patient, electronic- } \\
\text { patient, e-referral, e referral) }\end{array}$ & $\begin{array}{l}\text { électronique, } \mathrm{DME}^{\mathrm{d}} \text { (eg, gestion de cas électronique, dossier médical } \\
\text { électronique, patient électronique, référence électronique, référencement } \\
\text { électronique) }\end{array}$ \\
\hline net (eg, internet), web (eg, website) & net (eg, internet), toile, web (eg, site web) \\
\hline online & en ligne \\
\hline portals & portail \\
\hline sensor & senseur \\
\hline platform, (Headspace), (ACCESS ${ }^{\mathrm{e}}$ Open Minds ${ }^{\mathrm{f}}$ ) & plateforme, plate-forme \\
\hline social media (eg, social-media) & médias sociaux, réseaux sociaux \\
\hline $\begin{array}{l}\text { tech (eg, technology, communication technology, health information and } \\
\text { communication technology) }\end{array}$ & $\begin{array}{l}\text { techno (eg, technologie, technologique, technologies de l'information et } \\
\text { de la communication en santé) }\end{array}$ \\
\hline $\begin{array}{l}\text { tele (eg, telehealth, tele-health, tele-medicine, telemedicine, tele-mental- } \\
\text { health, telementalhealth, tele-psychiatry, telepsychiatry, tele-psychology, } \\
\text { telepsychology, tele-therapy, teletherapy) }\end{array}$ & $\begin{array}{l}\text { télé (eg, télé-santé, télé santé, télé-médecine, télé médecine, télé santé } \\
\text { mentale, télé-psychiatrie, télé psychiatrie, télé-psychologie, télé psycholo- } \\
\text { gie, télé-thérapie, télé thérapie) }\end{array}$ \\
\hline $\begin{array}{l}\text { video (eg, video-health, videohealth, video mental health, videomental- } \\
\text { health, video-psychiatry, videopsychiatry, video-psychology, videopsy- } \\
\text { chology, video-therapy, videotherapy) }\end{array}$ & $\begin{array}{l}\text { vidéo (eg, vidéo-santé, vidéo santé, vidéo santé mentale, vidéo-psychiatrie, } \\
\text { vidéo psychiatrie, vidéo-psychologie, vidéo psychologie, vidéo-thérapie, } \\
\text { vidéo thérapie) }\end{array}$ \\
\hline virtual (eg, virtual reality, virtual-reality), $\mathrm{VR}^{\mathrm{g}}$ & virtuel (eg, réalité virtuelle) \\
\hline
\end{tabular}

${ }^{\mathrm{a}}$ The original list of 9 words included $e$-mental health, tech, tele, net, internet, web, virtual, app, and digital.

${ }^{\mathrm{b}} \mathrm{EMR}$ : electronic medical record.

${ }^{\mathrm{c}}$ EHR: electronic health record.

dDME: dossier médical électronique.

eACCESS: Adolescent/young adult, Connecting to, Community-driven, Early, Strengths-based and Stigma-free services.

${ }^{\mathrm{f}}$ A national network connecting youth, families, caregivers, researchers, service providers, and policy makers to improve youth mental health care across Canada.

gVR: virtual reality. 
Table 2. Frequency of technology-related categories mentioned in the provincial/territorial mental health and addictions policy documents.

\begin{tabular}{lll}
\hline Category Examples of keywords & a & $\begin{array}{l}\text { Policy documents } \\
\left.\text { mentioning the cate- } \#^{\mathrm{c}}\right)^{\mathrm{c}} \\
\text { gory }^{\mathrm{b}}, \mathrm{n}\end{array}$ \\
\hline
\end{tabular}

Tele (télé in French) telehealth, TeleHealth, tele-health, telephone, 16 telepsychiatry, tele-psychiatry, telephone counselling, teleconferencing, telecounselling, telehealth network, telehealth consultation, video teleconferencing, tele-mental health, telemedicine, consultation téléphonique psychosociale

Phone (téléphone in phone, Kids Help Phone, telephone, telephone French) counselling, telephone screening, crisis phone lines, phone line, téléphone, phone-based coaching service

tech/techno

technology-based services, technology-based solutions, technologies, information technology, communication technology, technology, e-health technology, technology-based interventions, communication technologies, technological solutions, distance technology, emerging technology, evolving technologies, technologie

online

online counselling, online, online information, online cognitive behavioural therapy, online self-help supports, online training, online program, online options, online delivery, on-line resource, healthlineonline.ca, online gateways, provincial online hub, centralized online hub, online psychotherapy, ReachOut.com online platform, 211 online directory of community services (sk.211.ca), online and distance supports, online knowledge exchange $(\mathrm{KE})^{\mathrm{d}}$ space, online access point, online clinical treatments, online treatments, online resources, online directory, online tools, online modules, online innovation hub, online prevention, online clinical supports, online application, online chat capabilities, online experience, online government resources, online access, online peer support tools

line

distress lines, Mental Health Crisis Line, helpline, 10 Provincial Warm Line, crisis line, Problem Gambling Helpline, Kamatsiaqtut Help Line, crisis phone lines, HealthLine (811), healthlineonline.ca, phone line, community-based crisis lines, Kids Help Line, crisis helpline, line, crisis lines network

web web-based, website, mental health website, youth mental health websites, web resource, web application

virtual

virtual resources, virtual counselling, virtual solu- 6 tions, virtually, virtual reality, virtual teams, virtual mental health counselling

electronic

electronic health record, $\mathrm{EHR}^{\mathrm{e}}$, electronically, electronic client record, electronic mental health information and support, electronic information and support, electronic links

social media social media, social media communications

video conference, videos, videoconferencing, video 4 teleconferencing

app

mobile applications, app, application, online appli- 4 cation, web application
Alberta (2), British Columbia (3 and 4), Manitoba (5), Newfoundland and Labrador (7 and 8), Nova Scotia (9 and 10), Nunavut (13), Ontario (14 and 17), Prince Edward Island (18), Québec (19), Saskatchewan (20), Yukon (21 and 22)

Alberta (1), Newfoundland and Labrador (7 and 8), Nova Scotia (9 and 10), Nunavut (13), Ontario (14), Prince Edward Island (18), Québec (19), Saskatchewan (20), British Columbia (4), Yukon (21)

Alberta (1 and 2), Manitoba (5), New Brunswick (6), Newfoundland and Labrador (7 and 8), Ontario (16 and 17), Québec (19), Saskatchewan (20), Yukon (22)

Alberta (1), British Columbia (4), Newfoundland and Labrador (7 and 8), Nova Scotia (10), Nunavut (13), Ontario (14 and 15), Saskatchewan (20), Yukon (22)

Alberta (1), British Columbia (4), Newfoundland and Labrador (7 and 8), Nova Scotia (9 and 10), Nunavut (13), Saskatchewan (20), Yukon (21 and 22)

Alberta (1 and 2), British Columbia (4), Manitoba (5), New Brunswick (6), Newfoundland and Labrador (7 and 8), Ontario (14), Saskatchewan (20), Yukon (21)

Alberta (1 and 2), British Columbia (4), Newfoundland and Labrador (7 and 8), Yukon (22)

Alberta (1), Newfoundland and Labrador (7), Northwest Territories (11), Ontario (14), Prince Edward Island (18), Yukon (21)

British Columbia (3), Newfoundland and Labrador (7 and 8), Nunavut (13), Ontario (15)

Newfoundland and Labrador (7), Nova Scotia (9), Ontario (14), Saskatchewan (20)

Alberta (2), Nova Scotia (9), Yukon (21 and 22) 


\begin{tabular}{|c|c|c|c|}
\hline Category & Examples of keywords ${ }^{\mathrm{a}}$ & $\begin{array}{l}\text { Policy documents } \\
\text { mentioning the cate- } \\
\text { gory }^{\mathrm{b}}, \mathrm{n}\end{array}$ & $\begin{array}{l}\text { Province/territory mentioning the category (item } \\
\#)^{\mathrm{c}}\end{array}$ \\
\hline link & Health Link, links, electronic links & 4 & Alberta (1 and 2), Ontario (14), Yukon (21) \\
\hline text & text, text messages & 3 & $\begin{array}{l}\text { Newfoundland and Labrador ( } 7 \text { and } 8 \text { ), Nova Scotia } \\
\text { (10) }\end{array}$ \\
\hline e-mental health & $\begin{array}{l}\text { e-mental health, e-mental health services, e-Mental } \\
\text { Health and Addictions platform }\left(\mathrm{eMHA}^{\mathrm{f}}\right)\end{array}$ & 3 & $\begin{array}{l}\text { Newfoundland and Labrador (7 and 8), } \\
\text { Saskatchewan (20) }\end{array}$ \\
\hline platform & $\begin{array}{l}\text { platform, MyHealth platform, mental health and } \\
\text { addictions platform, e-Mental Health and Addic- } \\
\text { tions platform (eMHA), central platform, integrated } \\
\text { eMHA platform, online platform }\end{array}$ & 3 & Alberta (1 and 2), Saskatchewan (20) \\
\hline net & $\begin{array}{l}\text { internet, internet cognitive behavioural therapy, } \\
\text { iCBT }^{\mathrm{g}}\end{array}$ & 3 & $\begin{array}{l}\text { British Columbia (4), Newfoundland and Labrador } \\
\text { (7), Saskatchewan (20) }\end{array}$ \\
\hline chat & $\begin{array}{l}\text { chat, online chat capabilities, web-based chat capa- } \\
\text { bilities }\end{array}$ & 3 & British Columbia (4), Nova Scotia (10), Yukon (21) \\
\hline digital & digital therapy, digital view & 2 & Alberta (1), Newfoundland and Labrador (7) \\
\hline portal & portal, web-based portal & 2 & British Columbia (4), Ontario (14) \\
\hline mobile & mobile applications & 1 & Alberta (2) \\
\hline messag* & text messages & 1 & Nova Scotia (10) \\
\hline e-referral & e-referral tool & 1 & Alberta (1) \\
\hline
\end{tabular}

${ }^{a}$ Examples of keywords for each category were systematically extracted from the policy documents reviewed.

${ }^{\mathrm{b}}$ Compound keywords were counted twice to maintain a systematic approach to the keyword search of the policy documents. For example, telephone was counted once in tele and once in phone, and text messages was counted once in text and once in messag*.

${ }^{\mathrm{c}}$ The item number in parentheses reflects the item number in Multimedia Appendix 1.

${ }^{\mathrm{d}} \mathrm{KE}$ : knowledge exchange.

${ }^{\mathrm{e}}$ EHR: electronic health record.

feMHA: e-Mental Health and Addictions platform.

$\mathrm{g}_{\mathrm{iCBT}}$ : internet cognitive behavioural therapy.

\section{Results}

\section{Description of the MHA Policy Documents}

Most Canadian P/T governments (including Manitoba, New Brunswick, Northwest Territories, Prince Edward Island, Québec, and Saskatchewan) had 1 MHA policy document [45-50]. Alberta [51,52], British Columbia [37,42], Newfoundland and Labrador [53,54], Nova Scotia [38,55], Ontario [40,56-58], and Yukon [43,59] had two or more MHA policy documents. Nunavut did not have any MHA policy documents; instead, a statement of overall government directions and an action plan for suicide prevention in Nunavut were used in the analysis $[36,39]$. The types of policy documents we reviewed were visions or frameworks, strategies or action plans, and progress updates. The majority $(n=17 / 22)$ of the policy documents were focused on MHA policy strategies and action plans. The remaining 5 documents were about visions or frameworks for an MHA system ( $\mathrm{n}=2 / 22)$, progress updates on the MHA strategies or action plans $(n=1 / 22)$, or combined MHA strategies or action plans and progress updates $(n=2 / 22)$. We extracted data on the overview of each MHA policy document, particularly focusing on $\mathrm{P} / \mathrm{T}$ policy priorities addressed in the documents (see Multimedia Appendix 1).
Our synthesis of P/T MHA policy priorities identified 10 themes, with 7 themes being found in the policies of all $13 \mathrm{P} / \mathrm{Ts}$ : wellness/recovery/MHA promotion, prevention, and early intervention (eg, promoting good mental health, reducing stigma); service integration (eg, integration of service delivery to improve the currently fragmented system); collaboration (eg, promoting a multidisciplinary and collaborative team approach); children, youth, and families (eg, youth suicide prevention, strongest families program); improving access (eg, better access to services for remote, rural, and underserved communities; decreasing wait times and travel times); cultural safety and indigenous communities (eg, culturally relevant treatments and services, health equity for diverse populations); and use of technology (eg, sharing of evidence-based MHA information or services online). The remaining 3 themes were support for seniors $(n=12 / 13)$; innovation, improvement, and research $(n=$ $2 / 13)$; and reducing bullying $(n=6 / 13)$. As depicted in Multimedia Appendix 2, we organized the policy priorities as themes related to a population or a service; 3 of the priorities related to specific populations (children, youth, and seniors; and diversity of communities, such as indigenous communities, racialized groups, new arrivals, and persons with disability), and the remaining 7 were related to a service priority. 


\section{Use of Technology in the MHA Policy Documents}

Of the 39 keywords listed in Table 1, we identified 22 categories addressing the use of technology to deliver mental health services listed in Table 2. Table 2 also includes examples of keywords from each category that were used in the policy documents.

The 6 most common keyword categories were tele $(\mathrm{n}=16 / 22)$, phone $(\mathrm{n}=12 / 22)$, tech $(\mathrm{n}=11 / 22)$, online $(\mathrm{n}=10 / 22)$, line $(\mathrm{n}=10 / 22)$, and web $(\mathrm{n}=10 / 22)$. Among the 6 most common categories, 3 pertained to connecting people remotely in real-time: tele (eg, telephone, telehealth, telepsychiatry; $\mathrm{n}=16 / 22$ ), phone (eg, telephone counselling, crisis phone lines, phone-based coaching service; $\mathrm{n}=12 / 22$ ), and line (eg, distress lines, mental health crisis line, helpline; $\mathrm{n}=10 / 22)$. Policy documents also referred to technology-based services in general without detailing specific technologies. As such, tech $(\mathrm{n}=11 / 22)$ was the third most common category, followed by online $(\mathrm{n}=10 / 22)$, line $(\mathrm{n}=10 / 22)$, and web $(\mathrm{n}=10 / 22)$. Examples of words mentioned in this regard include technology-based services, technology-based solutions, and technologies; online counselling, online information, and online cognitive behavioural therapy; and web-based, website, and mental health website.

In this review, high-tech was used to describe technologies other than telephone-based services (eg, live chat on a website, the use of smartphone apps) and low-tech was used to describe telephone-based services (eg, crisis telephone help lines). High-tech categories were less common and included virtual $(\mathrm{n}=6 / 22)$, electronic $(\mathrm{n}=6 / 22)$, social media $(\mathrm{n}=5 / 22)$, video $(\mathrm{n}=4 / 22)$, app $(\mathrm{n}=4 / 22)$, and link $(\mathrm{n}=4 / 22)$. Examples of words mentioned in this regard include virtual resources, virtual counselling, and virtual reality; electronic health record and electronically; social media and social media communications; video conference and videos; mobile applications, app, and online application; and Health Link, links, and electronic links.

Other high-tech categories and broader approaches to the use of technology were mentioned at an even lower frequency: text (eg, text, text messages), e-mental health (eg, e-mental health, e-mental health services, e-Mental Health and Addictions platform), platform (eg, platform, MyHealth platform, mental health and addictions platform, online platform), net (eg, internet, internet cognitive behavioural therapy, $[i C B T]$ ), and chat (eg, chat, online chat capabilities, web-based chat capabilities) were each mentioned in 3 policy documents $(\mathrm{n}=3 / 22)$. Digital (eg, digital therapy, digital view) and portal (eg, portal, web-based portal) were each mentioned in 2 policy documents ( $\mathrm{n}=2 / 22)$. Mobile (eg, mobile applications), messag* (eg, text messages), and e-referral (eg, e-referral tool) were each mentioned in 1 policy document $(n=1 / 22)$. Overall, there was a diverse range of high-tech categories mentioned in the $\mathrm{P} / \mathrm{T}$ policy documents but these were mentioned at a much lower frequency compared to the low-tech categories.

Additionally, as shown in Multimedia Appendix 3, there was a high level of variation in the extent to which the policy documents referred to the 22 categories across the $13 \mathrm{P} / \mathrm{Ts}$ of Canada: Alberta $(n=14 / 22)$, Newfoundland and Labrador $(n=14 / 22)$, Yukon $(n=11 / 22)$, British Columbia $(n=10 / 22)$,
Ontario $(n=10 / 22)$, Saskatchewan $(n=10 / 22)$, Nova Scotia $(n=9 / 22)$, Nunavut $(n=5 / 22)$, Manitoba $(n=3 / 22)$, Prince Edward Island $(n=3 / 22)$, Québec $(n=3 / 22)$, New Brunswick $(n=2 / 22)$, and Northwest Territories $(n=1 / 22)$.

As noted above, more than half of the technology categories were mentioned in the policy documents of Alberta and Newfoundland and Labrador. Alberta's MHA action plans (2015, 2017-2020) emphasize developing and implementing a range of technology-based solutions (eg, websites, telehealth, mobile apps, virtual solutions) for MHA problems, and combining and enhancing resources that are already available (ie, telephone-based interventions such as Health Link and Kids Help Phone) [51,52]. For example, in its 2017-2020 MHA action plan, it states the following: "develop virtual, technology-based solutions to help people access tools, information and treatment to address addiction and mental health issues," and "share information on websites, telehealth, mobile, mobile applications, and other technologies" [51]. Similarly, Newfoundland and Labrador's vision for a renewed MHA system (2017) and MHA action plan (2017-2022) highlighted using a range of technologies (eg, including telehealth, videoconferencing, telephone crisis lines, online, text, virtual reality, social media, electronic health records, e-mental health) to achieve a full continuum of care and improve access to services $[53,54]$.

Regarding the policy documents that mentioned only a few technology categories (eg, Québec, New Brunswick, and the Northwest Territories), Quebec's action plan (2015-2020) mentioned developing new technologies to offer a network of youth-friendly MHA services, reiterated the availability of 24-7 psychosocial telephone consultations, and mentioned 2 institutions that aimed to promote mental health and new technologies: the Centre national d'excellence en santé mentale (CNESM) and the Service d'accueil, d'analyse, d'orientation et de référence des services sociaux généraux (AAOR) offering services over the phone [49]. In the New Brunswick Family Plan (2017), the only reference to technology was "information related to MHA treatment options are available to the public through various means, including web-based and print materials" [46]. The only mention of technology in the Northwest Territories strategic framework (2016-2021) pertained to electronic health records to promote the integration of service delivery [47]. For more details, refer to Table 2.

\section{Discussion}

Our objective for this policy review was to determine the extent to which technology is prioritized in mental health and addictions (MHA) policy documentation. Given that policy is context-based, we focused on the Canadian context. The methods that we used in this review can help to inform future efforts to monitor the evolutionary role of technology in mental health policy in Canada and abroad. Our findings have implications for policy makers, health care leaders, and researchers working towards improving access and quality of mental health services. 


\section{Principal Findings}

Our key findings are as follows. First, although all the documents referred to the use of technology for MHA care, there was a high level of variation in the extent to which technology was addressed across the P/T documents and how it was addressed. For example, Newfoundland and Labrador's MHA vision (2017) and action plan (2017-2022) described a variety of technology-based services (including telehealth, videoconferencing, telephone crisis lines, online, text, virtual reality, social media, electronic health records, e-mental health) to support access and continuum of care [53,54], whereas the strategic framework from the Northwest Territories (2016-2021) only mentioned electronic health records to promote the integration of service delivery [47], and Québec's action plan (2015-2020) only mentioned using technologies to offer MHA services to youth and providing psychosocial telephone consultations to the general population [49]. Second, only a few of the documents referred to the use of "high-tech" solutions, such as virtual reality and apps, with more than half mainly describing "low-tech" solutions, such as telephone-based helplines and telephone consultations for families. Considering the limitations of telephone-based interventions compared to other formats, such as video (eg, the latter resulting in fewer treatment errors and greater diagnostic and decision-making accuracy) [60] and considering mainstream society's increasing use of other formats of communication, such as texting, live chat, videoconferencing, and social media, addressing high-tech solutions in Canadian mental health policy is warranted. Third, there was inconsistency in the use of technology-related terminology across the documents, with the term e-mental health (the term used by the MHCC) $[10,30]$ rarely mentioned. Fourth, there was limited strategic focus and guidance in the policy documents on how to move forward with the successful implementation of technology-enabled services within the public mental health care system.

It is important to note that the P/T policy documents reflect governmental priorities for MHA services and did not have the purpose of providing a complete perspective on the use of technology. Although it may not be the intention of the policy documents to provide an exhaustive list of initiatives, describing exemplary evidence-based initiatives (eg, onlinetherapyuser.ca) that have received government funding is warranted to provide guidance to local health authorities. Moreover, the variation that we identified across $\mathrm{P} / \mathrm{Ts}$ on the degree of attention to technology in MHA care is noteworthy.

There are several implications of our findings. First, there is a need for strategic policy attention on the integration of technology in mental health; this requires addressing topics such as funding for implementation initiatives, infrastructure, regulation, capacity building, intersectoral collaboration, translation research, policy-research-practice partnerships, among others [11,12,29,32,33], as well as partnerships between researchers, practitioners, and policymakers. Advancement in these areas can be facilitated through interactions among policy makers and health services researchers specializing in the use of technology to deliver mental health care. Choi et al [61] provide several insights that can be helpful in this regard, including recommendations to incentivize collaboration among policy makers and scientists, use of knowledge brokers (to facilitate knowledge translation), and acknowledgment of the various issues affecting collaboration, including different languages and perspectives on evidence and different timeframes on achieving deliverables. Policy-making initiatives that facilitate the involvement of consumers, caregivers, and service is also important to consider.

Second, the inconsistency in the use of technology-related terms across the $\mathrm{P} / \mathrm{Ts}$ is not surprising given the evolving nature of the field itself and inconsistencies in the research literature. Nonetheless, this poses challenges to conducting future policy reviews to monitor advancement in the field. To address this issue, a living document of terminology, that is updated yearly, could be made accessible to mental health policy makers to encourage a level of standardization in the language used to refer to the use of technology in mental health care.

Third, the inconsistency in the degree of attention on technology across the $\mathrm{P} / \mathrm{T}$ documents may be a reflection that policy makers have limited knowledge on the evidence and potential of using technology in this field, highlighting the value for knowledge translation and collaborative initiatives among policy makers and researchers. It may also reflect the degree to which technology is prioritized at the front-line level of service delivery, raising the question of whether there is a lack of equity across the country in terms of the public's access to a wide range of services and interventions delivered through technology. This lack of attention in policy can contribute to a fragmented and unregulated approach to using technology to deliver mental health services in the country. Translational research for policy development and implementation planning is needed to better understand viewpoints from users, developers, providers, and policy makers on the implementation of technology-supported innovations, and to monitor the impact of implementation in terms of cost-effectiveness, access, and engagement, and the integration of models such as stepped care and clinical staging $[11,30]$.

Fourth, it will be important to monitor the extent to which rapid responses to delivering mental health care in the context of the COVID-19 pandemic to address the increased need for mental health support among the general population [62] and those with existing MHA conditions [63-66] are reflected in mental health policy. Several of the P/Ts have responded to COVID-19 by providing information to the public about COVID-19 and maintaining mental health via social media [67]; delivering cognitive behaviour therapy through text messaging with mental health professionals (eg, Alberta's Text4Hope); expanding existing online mental health counseling programs (eg, British Columbia's MindHealthBC); and expanding use of existing mental health services for children and youth, such as text, live chat, mobile apps, and phone-based services [68]. At the same time, it is unclear whether the rapidly deployed initiatives are sufficient for responding to the mental health impacts of COVID-19 and to what extent will these initiatives address the already existing gaps in the continuum of mental health care for those with chronic mental health conditions. Given this, there is a continued need for comprehensive policy and research to support a coordinated and evidence-based integration of 
technology in the Canadian mental health care system, during and after the COVID-19 pandemic.

Fifth, there is a further need for P/Ts and national collaboration to develop reliable and comprehensive environmental scans of the implementation of technology in Canadian mental health services, including analysis of failed attempts. Sixth, the development of a pan-Canadian framework for action that addresses the integration and coordination of technology in mental health service delivery can also help to guide P/T initiatives in this field.

Sixth, our findings provide a prepandemic baseline and replicable methods to inform a subsequent study of how the use of technology-supported services and innovations emerge as an important priority in mental health policy and practice, during and after the COVID-19 pandemic. Future research can also focus on examining how technology is considered in relation to the various mental health priorities addressed by policy documents (eg, use of technology in promoting wellness/recovery/MHA promotion, prevention, and early intervention; use of technology in promoting collaborative care; and use of technology in senior's mental health).

\section{Limitations}

We used an existing database (ie, the $19 \mathrm{P} / \mathrm{T}$ policy documents included in Sirotich et al [2]) as the main source of policy documents for our review. Therefore, it is possible that we might have missed some relevant documents. It is also acknowledged that there may be other documents potentially relevant to this review in these jurisdictions, but the documents we have identified outline government priorities for MHA care at the highest level and therefore are of primary importance for communicating a vision and strategy for mental health care services within a government's jurisdiction. It is also acknowledged that policies are frequently replaced; this review provides a report of relevant content available as of June 2019. In addition, we did not read through each page of each of the 22 documents to identify descriptions on the use of technology; although it was considered, it was deemed unfeasible by our team and also a potentially less reliable method of validation. We also believe that the final list of words we developed is quite comprehensive in its ability to capture the use of technology in mental health service delivery in these policy documents and that our methodology is both feasible and can be reliably replicated in future updated reviews.

\section{Conclusions}

This review on Canadian P/T mental health policy documents suggests that despite the potential for technology to improve access to and quality of MHA services, its implementation has been fragmented to date. Specifically, we identified large variations across Canadian P/T policy documents in terms of the types of technologies mentioned. Furthermore, many of the $\mathrm{P} / \mathrm{T}$ policy documents mentioned only low-tech solutions, such as telephone-based interventions. The review also shows the limited attention given in the mental health policy documents to the evidence-based literature on the use of technology to deliver mental health services, suggesting a potential gap in knowledge on the part of policy makers regarding the evidence in this field. This gap can be reduced through collaborative interactions among academics, policy makers, and practitioners facilitated through sectors of P/T governments (eg, research and innovation, health services). It would be worth considering repeating this review at regular intervals, which would document the advancement of technology in care delivery, including related responses to the COVID-19 pandemic.

\section{Acknowledgments}

SL is funded by the Canada Research Chairs Program.

\section{Authors' Contributions}

Building on previous work conducted by CEA, SL conceived the plan and protocol for the study. Under the supervision of SL, LS extracted and analyzed data, and HL validated the data extraction and analyses. SL wrote the first draft of the manuscript. All authors contributed to revisions of this manuscript and approved the final draft.

\section{Conflicts of Interest}

None declared.

\section{Multimedia Appendix 1}

Overview of mental health policy documents reviewed.

[DOCX File, $31 \mathrm{~KB}-$ Multimedia Appendix 1]

\section{Multimedia Appendix 2}

Recurrent themes identified in mental health and addictions (MHA) policy priorities across the 13 Canadian provinces and territories.

[DOCX File, 22 KB-Multimedia Appendix 2]

\section{Multimedia Appendix 3}

Frequency of technology-related categories mentioned by each province or territory. 
[DOCX File, 16 KB-Multimedia Appendix 3]

\section{References}

1. McDiarmid C. Health fact sheets: Mental health care needs, 2018. Statistics Canada. 2019. URL: https://www150. statcan.gc.ca/n1/en/pub/82-625-x/2019001/article/00011-eng.pdf?st=gzDwQVNH [accessed 2021-04-23]

2. Sirotich F, Adair CE, Durbin J, Lin E, Canning C. Mental health and addictions policy priorities and performance measurement frameworks. Healthc Manage Forum 2019 Mar;32(2):105-112. [doi: 10.1177/0840470418810273] [Medline: 30739488]

3. Kozloff N, Mulsant BH, Stergiopoulos V, Voineskos AN. The COVID-19 Global Pandemic: Implications for People With Schizophrenia and Related Disorders. Schizophr Bull 2020 Jul 08;46(4):752-757 [FREE Full text] [doi: 10.1093/schbul/sbaa051] [Medline: 32343342]

4. Li S, Wang Y, Xue J, Zhao N, Zhu T. The impact of COVID-19 epidemic declaration on psychological consequences: A study on active Weibo users. Int J Environ Res Public Health 2020 Mar 19;17(6):1-1 [FREE Full text] [doi: 10.3390/ijerph17062032] [Medline: 32204411]

5. Feijt M, de Kort Y, Bongers I, Bierbooms J, Westerink J, IJsselsteijn W. Mental health care goes online: Practitioners' experiences of providing mental health care during the COVID-19 pandemic. Cyberpsychol Behav Soc Netw 2020 Dec;23(12):860-864. [doi: 10.1089/cyber.2020.0370] [Medline: 32815742]

6. Bierbooms JJPA, van Haaren M, IJsselsteijn WA, de Kort YAW, Feijt M, Bongers IMB. Integration of online treatment into the "new normal" in mental health care in post-COVID-19 times: Exploratory qualitative study. JMIR Form Res 2020 Oct 08;4(10):e21344 [FREE Full text] [doi: 10.2196/21344] [Medline: $\underline{33001835}$ ]

7. Chen JA, Chung W, Young SK, Tuttle MC, Collins MB, Darghouth SL, et al. COVID-19 and telepsychiatry: early outpatient experiences and implications for the future. Gen Hosp Psychiatry 2020;66:89-95 [FREE Full text] [doi: 10.1016/j.genhosppsych.2020.07.002] [Medline: 32750604]

8. Moreno C, Wykes T, Galderisi S, Nordentoft M, Crossley N, Jones N, et al. How mental health care should change as a consequence of the COVID-19 pandemic. The Lancet Psychiatry 2020 Sep;7(9):813-824 [FREE Full text] [doi: 10.1016/S2215-0366(20)30307-2] [Medline: 32682460]

9. Christensen H, Griffiths K, Evans K. E-mental health in Australia: Implications of the Internet and related technologies for policy. Canberra: Commonwealth Department of Health and Ageing; 2002.

10. E-mental health in Canada: transforming the mental health system using technology. Mental Health Commission of Canada. URL: https://www.mentalhealthcommission.ca/sites/default/files/MHCC E-Mental Health-Briefing Document ENG 0. pdf [accessed 2021-04-23]

11. Lal S. E-mental health: Promising advancements in policy, research, and practice. Healthc Manage Forum 2019 Mar;32(2):56-62 [FREE Full text] [doi: 10.1177/0840470418818583] [Medline: $\underline{\text { 30739487] }}$

12. Lal S, Adair CE. E-mental health: A rapid review of the literature. Psychiatr Serv 2014 Jan 01;65(1):24-32. [doi: 10.1176/appi.ps.201300009] [Medline: 24081188]

13. Krausz R, Ramsey D, Wetterlin F, Tabiova K, Thapliyal A. Accessible and cost-effective mental health care using e-mental health (EMH). In: Javed A, Fountoulakis K, editors. Advances in Psychiatry. Cham, Switzerland: Springer; 2019:129-141.

14. Mohr DC, Burns MN, Schueller SM, Clarke G, Klinkman M. Behavioral intervention technologies: Evidence review and recommendations for future research in mental health. Gen Hosp Psychiatry 2013;35(4):332-338 [FREE Full text] [doi: 10.1016/j.genhosppsych.2013.03.008] [Medline: 23664503]

15. Liddy C, Rowan MS, Afkham A, Maranger J, Keely E. Building access to specialist care through e-consultation. Open Med 2013;7(1):e1-e8 [FREE Full text] [Medline: 23687533]

16. E-mental health: What's all the fuss about? NHS Confederation. URL: https://www.nhsconfed.org/resources/2013/01/ e-mental-health-whats-all-the-fuss-about [accessed 2021-04-23]

17. Lester D. Crisis Intervention and Counseling by Telephone. Springfield, IL: Charles C Thomas Publisher; 2002.

18. Hubley S, Lynch SB, Schneck C, Thomas M, Shore J. Review of key telepsychiatry outcomes. World J Psychiatry 2016 Jun 22;6(2):269-282 [FREE Full text] [doi: 10.5498/wjp.v6.i2.269] [Medline: 27354970]

19. Lal S, Abdel-Baki A, Sujanani S, Bourbeau F, Sahed I, Whitehead J. Perspectives of young adults on receiving telepsychiatry services in an urban early intervention program for first-episode psychosis: A cross-sectional, descriptive survey study. Front Psychiatry 2020;11:117 [FREE Full text] [doi: 10.3389/fpsyt.2020.00117] [Medline: 32194457 ]

20. Carlbring P, Andersson G, Cuijpers P, Riper H, Hedman-Lagerlöf E. Internet-based vs. face-to-face cognitive behavior therapy for psychiatric and somatic disorders: An updated systematic review and meta-analysis. Cogn Behav Ther 2018 Jan;47(1):1-18. [doi: 10.1080/16506073.2017.1401115] [Medline: 29215315]

21. Murray E. Web-based interventions for behavior change and self-management: Potential, pitfalls, and progress. Med 20 2012;1(2):e3 [FREE Full text] [doi: 10.2196/med20.1741] [Medline: 25075231]

22. Lal S, Gleeson J, Rivard L, D'Alfonso S, Joober R, Malla A, et al. Adaptation of a digital health innovation to prevent relapse and support recovery in youth receiving services for first-episode psychosis: Results from the Horyzons-Canada phase 1 study. JMIR Form Res 2020 Oct 29;4(10):e19887 [FREE Full text] [doi: 10.2196/19887] [Medline: 33118945] 
23. Price M, Yuen EK, Goetter EM, Herbert JD, Forman EM, Acierno R, et al. mHealth: A mechanism to deliver more accessible, more effective mental health care. Clin Psychol Psychother 2014;21(5):427-436 [FREE Full text] [doi: 10.1002/cpp.1855] [Medline: 23918764]

24. De Crescenzo F, Economou A, Sharpley AL, Gormez A, Quested DJ. Actigraphic features of bipolar disorder: A systematic review and meta-analysis. Sleep Med Rev 2017 Jun;33:58-69. [doi: 10.1016/j.smrv.2016.05.003] [Medline: 28185811]

25. Naslund JA, Aschbrenner KA, Marsch LA, Bartels SJ. The future of mental health care: peer-to-peer support and social media. Epidemiol Psychiatr Sci 2016 Apr;25(2):113-122 [FREE Full text] [doi: 10.1017/S2045796015001067] [Medline: 26744309]

26. Wiederhold BK, Riva G. Virtual reality therapy: emerging topics and future challenges. Cyberpsychol Behav Soc Netw 2019 Jan;22(1):3-6. [doi: 10.1089/cyber.2018.29136.bkw] [Medline: 30649958]

27. Musiat P, Tarrier N. Collateral outcomes in e-mental health: a systematic review of the evidence for added benefits of computerized cognitive behavior therapy interventions for mental health. Psychol Med 2014 Nov;44(15):3137-3150. [doi: 10.1017/S0033291714000245] [Medline: 25065947]

28. Linardon J, Shatte A, Messer M, Firth J, Fuller-Tyszkiewicz M. E-mental health interventions for the treatment and prevention of eating disorders: an updated systematic review and meta-analysis. J Consult Clin Psychol 2020 Nov;88(11):994-1007. [doi: 10.1037/ccp0000575] [Medline: 32852971]

29. Wozney L, Newton AS, Gehring ND, Bennett K, Huguet A, Hartling L, et al. Implementation of eMental Health care: viewpoints from key informants from organizations and agencies with eHealth mandates. BMC Med Inform Decis Mak 2017 Jun 02;17(1):78 [FREE Full text] [doi: 10.1186/s12911-017-0474-9] [Medline: 28577543]

30. McGrath P, Wozney L, Rathore S, Notarianni M, Schellenberg M. Toolkit for e-mental health implementation. Ottawa, ON: Mental Health Commission of Canada; 2018. URL: https://www.mentalhealthcommission.ca/sites/default/files/2018-09/ E_Mental_Health_Implementation_Toolkit_2018_eng.pdf [accessed 2021-04-23]

31. Brownson RC, Jones E. Bridging the gap: Translating research into policy and practice. Prev Med 2009 Oct;49(4):313-315. [doi: 10.1016/j.ypmed.2009.06.008] [Medline: 19555708]

32. Gehring ND, McGrath P, Wozney L, Soleimani A, Bennett K, Hartling L, et al. Pediatric eMental healthcare technologies: a systematic review of implementation foci in research studies, and government and organizational documents. Implement Sci 2017 Jun 21;12(1):76 [FREE Full text] [doi: 10.1186/s13012-017-0608-6] [Medline: 28637479]

33. Meurk C, Leung J, Hall W, Head BW, Whiteford H. Establishing and governing e-mental health care in Australia: A systematic review of challenges and a call for policy-focussed research. J Med Internet Res 2016 Jan 13;18(1):e10 [FREE Full text] [doi: 10.2196/jmir.4827] [Medline: 26764181]

34. E-mental health strategy for Australia. Australian Government, Department of Health and Aging. 2012 Jun. URL: https:/ /www1.health.gov.au/internet/publications/publishing.nsf/Content/mental-pubs-e-emstrat-toc [accessed 2021-04-23]

35. Measuring progress: Resources for developing a mental health and addictions performance measurement framework for Canada. Mental Health Commission of Canada. 2018 Jul. URL: https://www.mentalhealthcommission.ca/sites/default/files/ 2018-07/MHPMF final report eng 0.pdf [accessed 2021-04-23]

36. Sivumut abluqta: Stepping forward together. Government of Nunavut. 2014 Mar 20. URL: https://www.gov.nu.ca/sites/ default/files/sivumut_abluqta_-_eng.pdf [accessed 2021-04-23]

37. A pathway to hope: a roadmap for making mental health and addictions care better for people in British Columbia. Government of British Columbia. 2019 Jun 26. URL: https://www2.gov.bc.ca/assets/gov/british-columbians-our-governments/ initiatives-plans-strategies/mental-health-and-addictions-strategy/bcmentalhealthroadmap_2019web-5.pdf [accessed 2021-04-23]

38. Together we can: progress update. Nova Scotia Department of Health and Wellness. 2016 Jan. URL: https://novascotia.ca/ dhw/mental-health/reports/ProgressReport-Jan2016.pdf [accessed 2021-04-23]

39. Resiliency within an action plan for suicide prevention in Nunavut 2016-2017. Government of Nunavut. 2016 Mar. URL: https://www.gov.nu.ca/sites/default/files/resiliency within eng.pdf [accessed 2021-04-23]

40. Mental Health and Addictions Leadership Advisory Council. 2017. URL: http://www.health.gov.on.ca/en/common/ministry/ publications/reports/bmhmbh 2017/vision 2017.pdf [accessed 2021-04-23]

41. B.C.'s mental health and substance use strategy 2017-2020. Government of British Columbia. 2017. URL: http://www. llbc.leg.bc.ca/public/pubdocs/bcdocs2017_2/681562/mental-health-substance-use-strategy.pdf [accessed 2021-04-23]

42. A path forward: BC first nations and aboriginal people's mental wellness and substance use 10-year plan. First Nations Health Authority, British Columbia Ministry of Health \& Health Canada. 2013 Mar 18. URL: https://www.fnha.ca/Documents/ FNHA_MWSU.pdf [accessed 2021-04-23]

43. Mulvale G, Kutcher S, Winkup J. A child and youth mental health and addiction framework for the Yukon. Government of Yukon. Hamilton, ON: McMaster University; 2014. URL: https://yawc.ca/files/ a-child-youth-mental-health-addictions-framework-for-yukon-2014.pdf [accessed 2021-04-23]

44. Hsieh H, Shannon SE. Three approaches to qualitative content analysis. Qual Health Res 2005 Nov;15(9):1277-1288. [doi: 10.1177/1049732305276687] [Medline: 16204405]

45. Rising to the challenge: A strategic plan for the mental health and well-being of Manitobans. Government of Manitoba. 2011 Jun. URL: https://www.gov.mb.ca/health/mh/docs/challenge.pdf [accessed 2021-04-23] 
46. New Brunswick family plan: Supporting those with addictions and mental health challenges. Government of New Brunswick. 2017 May. URL: http://www2.gnb.ca/content/dam/gnb/Departments/eco-bce/Promo/family plan/mentalhealth.pdf [accessed 2021-04-23]

47. Mind and spirit: Promoting mental health and addictions recovery in the Northwest Territories, strategic framework 2016-2021. Government of Northwest Territories. 2016 Nov 03. URL: https://www.hss.gov.nt.ca/sites/hss/files/resources/ mind-spirit-promoting-mental-health-addictions-recovery-nwt-strategic-framework-web.pdf [accessed 2021-04-23]

48. Moving forward together: Mental health and addiction strategy. Government of Prince Edward Island. 2016 Nov 14. URL: https://www.princeedwardisland.ca/sites/default/files/publications/peimentalhealthaddictionsstrategy moving forward.pdf [accessed 2021-04-23]

49. Faire ensemble et autrement: Plan d'action en santé mentale 2015-2020. Ministère de la Santé et des Services Sociaux. 2015 Oct 9. URL: https://publications.msss.gouv.qc.ca/msss/fichiers/2017/17-914-17W.pdf [accessed 2021-04-23]

50. Working together for change: A 10-year mental health and addictions action plan for Saskatchewan. Government of Saskatchewan. 2014 Dec 1. URL: https://www.saskatchewan.ca/government/

health-care-administration-and-provider-resources/saskatchewan-health-initiatives/mental-health-and-addictions-action-plan [accessed 2021-04-23]

51. Valuing mental health: next steps. Alberta Government. 2017. URL: https://tinyurl.com/8awmmkkh [accessed 2021-04-23]

52. Valuing mental health: report of the Alberta mental health review committee 2015. Alberta Government. 2016 Feb 23.

URL: https://open.alberta.ca/dataset/d8413604-15d1-4f15-a979-54a97db754d4/resource/ 1a5e7a16-3437-428e-b51f-4ba9201767a4/download/alberta-mental-health-review-2015.pdf [accessed 2021-04-23]

53. Towards recovery: A vision for a renewed mental health and addictions system for Newfoundland and Labrador. All-Party Committee on Mental Health and Addictions. 2017 Mar. URL: https://www.gov.nl.ca/hcs/files/all-party-committe-report. pdf [accessed 2021-04-23]

54. The way forward. Towards recovery: the mental health and addictions action plan for Newfoundland and Labrador. Government of Newfoundland and Labrador. 2017 Jun 30. URL: https://www.gov.nl.ca/hcs/files/ mentalhealth-committee-mentalhealth-pdf-mentalhealth-addictions-plan.pdf [accessed 2021-04-23]

55. Together we can: the plan to improve mental health and addictions care for Nova Scotians. Nova Scotia Department of Health and Wellness. 2012 Apr 23. URL: https://novascotia.ca/dhw/mental-health/reports/

Mental-Health-and-Addictions-Strategy-Together-We-Can.pdf [accessed 2021-04-23]

56. Mental Health and Addictions Leadership Advisory Council. 2015. URL: http://www.health.gov.on.ca/en/common/ministry/ publications/reports/bmhmbh/mental health adv council.pdf [accessed 2021-04-23]

57. Mental Health and Addictions Leadership Advisory Council. 2016. URL: http://www.health.gov.on.ca/en/common/ministry/ publications/reports/bmhmbh 2016/moving forward 2016.pdf [accessed 2021-04-23]

58. Open minds, healthy minds. Ontario's comprehensive mental health and addictions strategy. Government of Ontario. 2011 Jun. URL: http://www.health.gov.on.ca/en/common/ministry/publications/reports/mental_health2011/mentalhealth_rep2011. pdf [accessed 2021-04-23]

59. Forward together. Yukon mental wellness strategy 2016-2026. Yukon Health and Social Services. 2016 Jun. URL: https:/ /yawc.ca/files/forward-together-yukon-mental-wellness-strategy-2016-26.pdf [accessed 2021-04-23]

60. Rush KL, Howlett L, Munro A, Burton L. Videoconference compared to telephone in healthcare delivery: a systematic review. Int J Med Inform 2018 Oct;118:44-53. [doi: 10.1016/j.ijmedinf.2018.07.007] [Medline: 30153920]

61. Choi BCK, Pang T, Lin V, Puska P, Sherman G, Goddard M, et al. Can scientists and policy makers work together? J Epidemiol Community Health 2005 Aug;59(8):632-637 [FREE Full text] [doi: 10.1136/jech.2004.031765] [Medline: 16020638]

62. Salari N, Hosseinian-Far A, Jalali R, Vaisi-Raygani A, Rasoulpoor S, Mohammadi M, et al. Prevalence of stress, anxiety, depression among the general population during the COVID-19 pandemic: a systematic review and meta-analysis. Global Health 2020 Jul 06;16(1):57 [FREE Full text] [doi: 10.1186/s12992-020-00589-w] [Medline: $\underline{32631403]}$

63. Brown E, Gray R, Lo Monaco S, O'Donoghue B, Nelson B, Thompson A, et al. The potential impact of COVID-19 on psychosis: a rapid review of contemporary epidemic and pandemic research. Schizophr Res 2020 Aug;222:79-87 [FREE Full text] [doi: 10.1016/j.schres.2020.05.005] [Medline: 32389615]

64. Hawke LD, Barbic SP, Voineskos A, Szatmari P, Cleverley K, Hayes E, et al. Impacts of COVID-19 on youth mental health, substance use, and well-being: a rapid survey of clinical and community samples. Répercussions de la COVID-19 sur la santé mentale, l'utilisation de substances et le bien-être des adolescents: un sondage rapide d'échantillons cliniques et communautaires. Can J Psychiatry 2020 Oct;65(10):701-709 [FREE Full text] [doi: 10.1177/0706743720940562] [Medline: $\underline{\text { 32662303] }}$

65. Anmella G, Arbelo N, Fico G, Murru A, Llach CD, Madero S, et al. COVID-19 inpatients with psychiatric disorders: real-world clinical recommendations from an expert team in consultation-liaison psychiatry. J Affect Disord 2020 Sep 01;274:1062-1067 [FREE Full text] [doi: 10.1016/j.jad.2020.05.149] [Medline: 32663933]

66. Warfield SC, Pack RP, Degenhardt L, Larney S, Bharat C, Ashrafioun L, et al. The next wave? Mental health comorbidities and patients with substance use disorders in under-resourced and rural areas. J Subst Abuse Treat 2021 Feb;121:108189. [doi: 10.1016/j.jsat.2020.108189] [Medline: 33162261] 
67. Provincial and territorial resources for COVID-19. Government of Canada. 2020 Oct 16. URL: https://www.canada.ca/en/ public-health/services/diseases/2019-novel-coronavirus-infection/symptoms/provincial-territorial-resources-covid-19.html [accessed 2021-04-23]

68. Provincial and territorial COVID-19 resources. Mental Health Commission of Canada. 2020. URL: https://www. mentalhealthcommission.ca/English/provincial-and-territorial-covid-19-resources [accessed 2021-04-23]

\author{
Abbreviations \\ AAOR: Service d'accueil, d'analyse, d'orientation et de référence des services sociaux généraux \\ CNESM: Centre national d'excellence en santé mentale \\ EHR: electronic health record \\ EMR: electronic medical record \\ ICT: information and communication technology \\ iCBT: internet cognitive behavioural therapy \\ MHA: mental health and addictions \\ MHCC: Mental Health Commission of Canada's \\ P/T: provincial/territorial
}

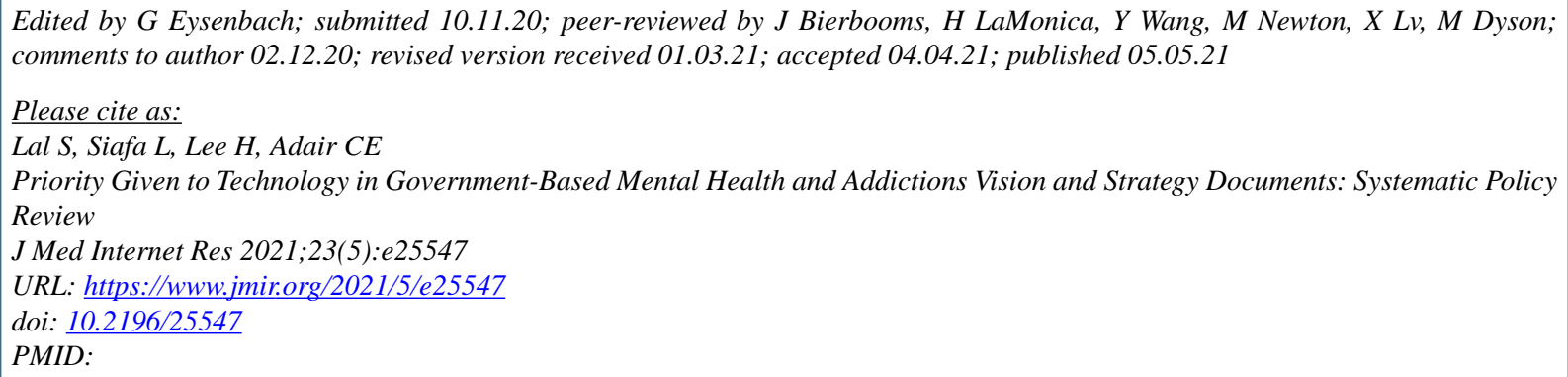

(C)Shalini Lal, Lyna Siafa, Hajin Lee, Carol E Adair. Originally published in the Journal of Medical Internet Research (https://www.jmir.org), 05.05.2021. This is an open-access article distributed under the terms of the Creative Commons Attribution License (https://creativecommons.org/licenses/by/4.0/), which permits unrestricted use, distribution, and reproduction in any medium, provided the original work, first published in the Journal of Medical Internet Research, is properly cited. The complete bibliographic information, a link to the original publication on https://www.jmir.org/, as well as this copyright and license information must be included. 